\title{
Decision-Making in Foreign Language Reduces Emotional Arousal
}

\author{
Josef N. Lazar, Atar Stern, Ran Cohen \\ The Department of Psychology, Tel-Hai College, Upper Galilee, Israel \\ Email: yosibcn@gmail.com
}

Received 17 October 2014; revised 14 November 2014; accepted 11 December 2014

Copyright (C) 2014 by authors and Scientific Research Publishing Inc.

This work is licensed under the Creative Commons Attribution International License (CC BY). http://creativecommons.org/licenses/by/4.0/

(c) $($ )

\section{Abstract}

The study of bilingual's qualities suggests that their decision-making process might differ in both languages. A recent research by Keysar, Hayakawa \& An (2012) investigated the phenomenon of reduction in emotional reactivity in the second language on decision-making process, especially amongst bilinguals who acquired their second language later in life, often in a more formal setting (Pavlenko, 2005). This research intended to show a more convincing argument regarding this phenomenon by checking the participants' physiological arousal during the decision processes, using three physiological measures (Electrocardiogram, Galvanic Skin Response and Electroencephalogram). In congruence with the detachment effect theory, our hypothesis is that when bilinguals think in their foreign language, less emotional reactivity will be shown. The participants ( $N=69$ ) are students from Tel-Hai academic college. All of them, native Hebrew speakers who speak English as a foreign language, accomplish a decision-making task (Robert's apperception test for children 2). All the tasks were performed in both languages, one after the other, while being connected to the physiological measures which measured their arousal in-vivo. In accordance with our hypothesis, a significant difference was found in the task. A significant difference was also found in the Electroencephalogram of the right prefrontal cortex but in the opposite direction to our initial hypothesis. No other significant differences were found. The explanation for these results might derive from a different phenomenon that is well documented, and the anxiety that stem from the need of using a foreign language (Woodrow, 2006). Although we were not able to demonstrate an emotional detachment effect on a physiological level, we believe that holding the anxiety variable constant will yield that effect in future studies.

\section{Keywords}

Decision-Making, Emotion, Arousal, Foreign Language 


\section{Introduction}

Bilingual's studies suggest that thinking in different languages has an intrinsic effect on our lives. This effect has a substantial impact on cognitive, emotional and physiological aspects (Bialystok, 2010). Some of these studies describe reduction in emotional reactivity in the second language (Schwanberg, 2010; Harris, Aycicegi, \& Gleason, 2003; Anooshian \& Hertel, 1994). This phenomenon is mostly found amongst bilinguals who acquire their second language later in life, often in a more formal setting (Pavlenko, 2005). The phenomenon has been well studied, but only recently during decision making processes, an essential component of our thinking ability. A recent research by Keysar, Hayakawa, \& An (2012) suggests that in the decision making process, a foreign tongue reduces emotional bias. Past researches have shown a reduction in emotional reactivity in a foreign language using physiological measures, but not during decision making processes. In the current research we will use physiological measures that allow us to make a more convincing argument regarding this phenomenon.

Freud and his disciples found that their bilingual patients would sometimes prefer the use of their second language when they were discussing anxiety related topics (Freud, 1893). It appeared that they were able to distance themselves this way; they were able to continue discussing arousing subjects without becoming overwhelmed with emotion. Findings from clinical studies confirm that descriptions in the speaker's second language may sound detached, as opposed to first language descriptions that clearly express emotional content, which is detected by increased pitch and even crying (Movahedi, 1996). This phenomenon has been further explored by many researches (Halberstadt, 1994; Pavlenko, 2005, 2012), and was conceptualized by Marcos (1976) as the detachment effect.

Recent findings lead to the assumption that the decrease in emotional appearance is yielded from the possibility that the use of a second language requires a deeper and more deliberate mode of thinking, due to lack of native fluency. The use of the native tongue may be more intuitive and hence more emotional (Keysar et al., 2012). The emotional reaction is attenuated to taboo words and other emotional laden words when foreign language is used in comparison to native tongue (Bowers \& Pleydell-Pearce, 2011), as has been demonstrated by subjective methods as well as electro-dermal responses (Caldwell-Harris \& Aycicegi-Dinn, 2009).

Another possible explanation for these results is that the acquisition of a second language happens in a different context, often in more formal environment (e.g. school). This environment, unlike the one during childhood, does not provide many opportunities for integration of words with specific feelings and thus might lead to development of “disembodied” emotional reactions (Dewaele, 2010; Pavlenko, 2005). However, the findings mentioned above should be considered with caution, because when studying bilingual's abilities, one needs to consider many different factors in play.

The definition of the concept "bilingual speakers" defer in different researches according to the order, the age, the language proficiency and the context of acquiring the two languages (Dewaele, 2010). In order to describe the two, a common chronological order was used, L1 for the first acquired language and L2 for the second language. Acquisition second language age defer from one case to another; it may be on birth, early childhood, etc. As we've mentioned before, the detachment effect is particularly prominent amongst late bilinguals; also named "coordinate bilinguals", speakers who acquired their L2 after the age of 12, and mainly in a formal context (Pavlenko, 2012; Altarriba, 2002). Recent findings suggest that late bilinguals make less emotional decisions when using L2 than that when using L1 (keysar et al., 2012).

\section{Decision Making}

Decision-making is one of four important abilities that helps us navigates our life in this world. The other three abilities are: interpretation, reasoning and judgment (Blanchette \& Richards, 2010). These four processes are well accepted today as the factors that distinguish humans from the rest of the mammals (Blanchette \& Richards, 2010).

When studying decision-making, the ways subjects choose one option among two or more possibilities were investigated, in order to explain the reason that lies under the chosen decision. Gambling experimental tasks are procedures in which subjects have to gamble on the bases of value (outcome) and probability; other studies are self-report of actual risky behaviors (Blanchette \& Richards, 2010). Recently, due to developments in the technological world, advanced physiological techniques as well as apparatus are available (e.g. fMRI, MRI, PET, etc.). So revealing the neural basis of successful and unsuccessful decision-making is possible (Naqvi, Shiv, \& Bechara, 2006). 
For many years, the decision-making process considered to be pure cognition (Simon, 1956; Medin, Busemeyer, \& Hastie, 1995), perhaps due to its rationalistic roots (Slovic, Finucane, Peters, \& MacGregor, 2007). Tversky \& Kahneman were the first ones who systematically violated the normative assumptions of the principles of decision making in humans. They demonstrated the extent of emotional influence on high risk decisions or during vague situations (Tversky \& Kahneman, 1974; Kahneman, Lovallo, \& Sibony, 2011). Zajonc, (1980) was another pioneer in this field. He also challenged the classic "rational decision-making" theory by saying that affect has an important role on every day decisions. He postulated that, actually, it might be the first reaction that occurs automatically in response to a stimuli and in turn guiding our information processing and judgment. Zajonc argued that “we don't just see a house”: We see a handsome house, an ugly house, or a pretentious house" (p. 154). Most "rational processes", like weighting the pros and cons of one's decision, are actually no more than the way one feels about a specific thing. We buy the car we "like" and later justify our choice (Zajonc, 1980). There's no doubt regarding the importance of analytical decision-making in specific situations, but relying on emotions, intuition and automaticity is a largely more efficient manner to make your way in this challenging, demanding and sometimes overwhelming world (Epstein, 1994).

More evidence, regarding the emotional dimension's weight, while making a decision, comes from the field of pathology. For instance, people who got injured in their Ventro-medial pre frontal cortex (vmPFC) and their cognitive abilities examined and found to be intact, yielded the understanding that the vmPFC is involved in our ability to use emotions for moderating decisions (Bechara, Damasio, Damasio, \& Lee, 1999), especially when the outcome (reward/punishment) is unclear (Naqvi et al., 2006).

Recent neuroimaging studies confirm the results mentioned above and strengthen them from the anatomical perspective. De Martino, Kumaran, Seymour, \& Dolan (2006) asked participants to gamble on the computer while scanning their brain on fMRI. They used Kahneman \& Tversky "framing effect" manipulation. The results were clear, participants who reacted according to their initial tendency (i.e. significantly less gambling in the gain frame than in the loss frame), showed increased activity in their amygdala. An area associated with emotions regulation, and in humans also in charge of extracting relevant emotional aspects out of the information present (Adolphs, 2006). On the other hand, increased activation was observed in the orbital Medial prefrontal cortex (OMPFC), in participants whose decisions were more rational (De Martino et al., 2006). These evidences support the theories that emotions are largely integrated in, and regulate the decisions we make on daily basis, especially complex ones.

Keysar et al., (2012) discovered recently that using a foreign language reduces decision-making biases. In their experiment, the participants, late bilinguals, were confronted with a decision-making task. While using their native tongue, the participant's decisions showed a significant bias towards risk preference. However, this bias had disappeared when they were using their second language. They concluded that their results were most likely due to a reduction in affect that is associated with using L2. Although this experiment may contribute evidence towards a "detachment effect" in decision making, it would have been more convincing and helped us differentiate better between a reduction in affect and enhanced deliberation, if more objective, physiological measures, such as skin conductivity methods, were involved (Pavlenko, 2012).

This leads us to our hypothesis, that when late bilinguals think in their foreign language less emotional reactivity will be shown.

\section{Method}

\subsection{Participants}

Sixty-nine students from Tel-Hai academic college in upper galilee regional council participated in this experiment. All of them were native Hebrew speakers who speak English as a foreign language.

\subsection{Materials and Apparatus}

Electroencephalogram (EEG). In order to assess the areas of the brain in which enhanced activity is reflected during the task, we connected the subject to the EEG, an apparatus that allows tracking the neural activity in the brain in millisecond (MS) resolution (Vecchiato, Astolfi, Fallani, Cincotti, Mattia, Salinari, \& Babiloni, 2010). Two electrodes were connected to the prefrontal cortex (PFC) one on each side. The PFC is associated with higher cognitive processes such as decision making (Blanchette \& Richards, 2010). 
Electrocardiogram (ECG). In order to assess the emotional arousal of the participants we measured it with the physiological apparatus ECG. Heart rate is another index controlled by the autonomic system. The vagal nerve controls the body heart rate (Groves \& Brown, 2005). The firing strength of the vagal nerve has been associated with emotions' cross-regulating. Thus, monitoring the subject's Heart rate (HR) can give an indication on one's internal emotional state (Appelhans \& Luecken, 2006). Advances in technology allow us to measure and record the Heart Rate Variation (HRV) accurately on real-time. ECG is an accepted HRV measuring device (Pumprla, Howorka, Groves, Chester, \& Nolan, 2002). It Records of the surface electrical activity of the heart using electrodes placed on skin and indicates on the cardiac cycle (Burns, 2013). Evidence from a recent study indicates that higher levels of HRV associated with more accurate detection of expressed emotions (Quintana, Guastella, Outhred, Hickie, \& Kemp, 2012).

Galvanic Skin Response (GSR). In order to assess the emotional arousal of the participants we also measured it using the physiological apparatus GSR. Fight or Flight response is being activated when our physical and mental health is in danger (Hugdahl, 1995). The sympathetic nervous system induces some responses; include elevation in heart rate, tensing facial muscles and electrical conductivity of our skin (electrodermal reactivity). The stimulus boosts the level of adrenaline in the blood which in turn increases sweating of palms and fingertips. This reaction called Skin Conductivity Response (SCR) and being measured quantitatively by the apparatus mentioned, through fingertip electrodes (Pavlenko, 2012). The reactivity usually starts $1-1.5$ seconds after the stimulus and may last 2 - 6 seconds (Harris, 2004). It's been well documented, already in the mid-20th century, that listening or reading emotion-laden words such as taboo-words and swears; elicit higher SCR than in neutral words (Bingham, 1943; Manning \& Melchiori, 1974; McGinnies, 1949). GSR is considered to be a sensitive and convenient way to distinguish changes in the body's arousal system related to emotion, cognition and attention (Critchley, 2002).

Beck Depression Inventory II (BDI-II). In order to assess the initial affective state of the participants we used the Hebrew version the BDI-II (Ofer, 1999). The BDI-II is a widely used 21-item self-report inventory measuring the severity of depression in adolescents and adults (Beck, Steer, \& Brown, 1996). Subjects rated whether they have experienced each symptom during the past few weeks on a 4-point rating scale $(0-3)$ for each item. Cronbach's coefficient alpha reliabilities for the Hebrew version of the scale are 0.91 (Ofer, 1999).

Positive and Negative Affect Schedule (PANAS). In order to assess the initial affect levels of the participants we used the Hebrew version of the PANAS; a brief and easily administered measure of positive and negative affect (Watson, Clark, \& Tellegen, 1988). It consists of 10-item Positive Affect (PA) (Items: 1, 3, 5, 9, 10, 12, 14, 16, 17, 19) and Negative Affect (NA) (Items: 2, 4, 6, 7, 8, 11, 13, 15, 18, 20) scales that comprise the 20-item inventory. The items are rated on a 5 -point scale $(1=$ very slightly or not at all, $2=$ a little, $3=$ moderately, $4=$ quite a bit, 5 = extremely). Cronbach's coefficient alpha reliabilities for the scales are 0.89 and 0.85 , for positive effect and negative effect, respectively (Shachar, 2005).

State-Trait Anxiety Inventory (STAI). In order to assess the initial anxiety levels of the participants we used the Hebrew version of the STAI (Ben-Zur, 1998). The STAI is a self-report questionnaire that consists of two separate measures for state and trait anxiety (Spielberger, Gorsuch \& Lushene, 1970). Strait anxiety represents a condition characterized by subjective feelings of tension, apprehension and strong activity of the autonomic nervous system. Whilst, trait anxiety represents steady individual changes in anxiety proneness and a general tendency to develop anxiety in response to perceived threats in one's environment (McDonald \& Spielberger, 1983). Cronbach's coefficient alpha reliabilities for the Hebrew version of the scales are 0.84 and 0.82 , for trait and state scales, respectively (Ben-Zur, 1998).

Robert's apperception test for children 2 (RATC-II). The Robrets-2 is used to clinically evaluate children between 6 - 18 years of age. It aims to provide a comprehensive and detailed understanding of the child's social perception (Roberts, 2013). The test is comprised of 16 picture cards, drawings of different situations, which in response to, the child tells a story. The outcomes are measured using 7 different scales that comprise the RATCII: problem identification, outcome, available resources, emotion, resolution and unusual responses, and a theme overall overview. For the purpose of this research we used 2 pictures from the test and evaluated four of them: the participant's available resources, problem identification, resolution and emotion.

English exam. In line with other researchers we checked for the level of proficiency of the second language, to ensure that the subjects understand the matter in hand. The exam tested for reading comprehension and included a short passage followed by five related questions. The minimum criterion was at least three correct answers determined by the median result. The text and the questions were taken from the psychometric test, De- 
cember 2011 edition (National institute for testing and evaluation, 2011).

\subsection{Procedure}

In a counterbalanced design, the participants were randomly assigned to perform a decision making task using a different language each time. Half of the participants began the task with Hebrew (L1) and continued with English (L2), and the other half began with L2 and then continued to using L1. The participants were attached to three different physiological measures, Electroencephalogram (EEG), Electrocardiogram (ECG) and Galvanic Skin Response (GSR), throughout the entire experiment. Each participant was asked to sign on a written consent before starting the procedure (Appendix 1). To avoid unrelated emotional bias, each participant first watched an emotional neutral video clip; followed by three self-report questionnaires for assessing the emotional base level (Appendix 2). Furthermore, to ensure the participants have a minimum required level of fluency in the second language, we administered a short comprehension exam in English. We excluded participants who didn't demonstrate a clear understanding of the exam requirements and/or had irregular scores according to the emotion assessment questionnaires.

\subsection{Maintaining the Integrity of the Specifications}

The template is used to format your paper and style the text. All margins, column widths, line spaces, and text fonts are prescribed; please do not alter them. You may note peculiarities. For example, the head margin in this template measures proportionately more than is customary. This measurement and others are deliberate, using specifications that anticipate your paper as one part of the entire journals, and not as an independent document. Please do not revise any of the current designations.

\section{Results}

In the current research we tested for significant differences of physiological arousal among bilinguals, using native-tongue versus second language, during a decision making task. To examine our participants' arousal we used three different electrophysiological measures; Also, the task used in the decision making process was scored for emotional arousal. Of the original cohort of subjects, 19 (28\%) were excluded due to lack of L2 proficiency. With respect to earlier results, we hypothesized that late bilinguals will show less emotional reactivity during the task while using their second language.

To test our hypothesis we ran a series of paired samples t-tests, to find out if there were any significant differences in electrophysiological measures or in the scores of the RATC-II while using mother-tongue language or second language. A significant difference was found for the RATC-II $(\mathrm{t}(46)=-2.054, p=0.046)$, mean score for the mother-tongue, Hebrew $(M=6.09$, $S D=3.09)$ was higher than the second language $(M=5.0, S D=$ 2.29). The other only significant difference was found for the EEG of the front-right pre-frontal cortex $(\mathrm{t}(49)=$ $-2.05, p=0.046)$, mean score for the mother-tongue $(\mathrm{M}=-4 \times 10-7, \mathrm{SD}=0.00003)$ was lower than the second language $(M=2 \times 10-5, S D=0.00003)$. For the EEG of the front-left prefrontal cortex, ECG and GSR no significant difference were found $(p>0.05)$.

We used a repeated measures ANOVA test to check for interactions between the RATC-II task and the electrophysiological measures—but no significant interactions were found $(p>0.05)$.

\section{Discussion}

In this research we hypothesized that bilinguals will present with more physiological arousal during a decision making task in their native tongue (L1) as opposed to their second language (L2). A significant difference was found for the scoring of the decision making task, that was in accordance with our hypothesis. Namely, the participants scored higher on the emotional scales of the RATC-II, while using L1. Many studies have demonstrated that the use of the native tongue maybe more intuitive and hence more emotional (Keysar et al., 2012; Dewaele, 2010; Pavlenko, 2005) and there results are not surprising. A significant difference was also found for the front right side of the pre frontal cortex (FR-PFC) EEG results. However, the participants showed higher arousal levels while using L2, as opposed to the results of the RATC-II and our initial hypothesis. No other significant differences were found including interactions between the RATC-II and the electrophysiological measures.

The RATC-II is a projective test built to measure emotional response. The images of the test depict mostly 
conflicts; hence, it is safe to assume they will typically elicit negative effect. Studies found that the FR-PFC is more active during appraisal of negative affect and that the front left side (FL) of the PFC is more active during positive affect (Davidson \& Irwin, 1999). This finding could explain why the results were significant for the FR-PFC EEG and not for the FL-PFC, meaning that the participants' perceptions were reflected in the results.

The above mentioned outcome is not in line with our hypothesis; the use of L2 induced higher arousal than in L1. There could be several possible explanations for this result. In our opinion, the main explanation could be the influence of second language anxiety. Language anxiety is a kind of situational anxiety related to oral expression (e.g. writing) in the second language (Argaman \& Abu-Rabia, 2002). Studies show that this effect is universal, and is common among students that English is their second language (Woodrow, 2006; Pappamihiel, 2002; MacIntyre \& Gardner, 1989). Particularly, The Haifa study, an Israeli sample of seventh graders, found that although the English language is a major part in Israeli's everyday life, it is still a major cause for anxiety (Argaman \& Abu-Rabia, 2002). 85\% (58 out of 68) of the participants in this sample reported at least low levels of anxiety before taking an English exam. The results demonstrated that reading and writing abilities were "adversely affected by language anxiety" (Argaman \& Abu-Rabia, 2002). Some of the participants choose not to take part in the exam and argued that "Writing sentences in English is not easy and I do not want to! Do not think in your study that I am a retard" or "It is difficult for me to write in English". Although, our participants were significantly older and have passed the English acceptance criterion for higher education, similar saying were expressed in the current research (e.g. "I can’t go on any further, my English is not good”, "Whoever reads this will think I'm stupid", "I have many spelling mistakes" etc.). It is common knowledge that students in Israel suffer from anxiety in English, thus, we accounted for it and made an effort to lower anxiety levels by stating that spelling mistakes are of no importance and that the writing task is not time limited. Nevertheless, we believe that the second language anxiety effect might be the main explanation for the insignificance in most of our results, as opposed to previous studies (Keysar et al., 2012, Pavlenko, 2012, 2005). Unfortunately, we didn't test for anxiety levels before the English screening test; hence, we can't determine that indeed the second language anxiety had such an effect on our results.

Another possible explanations might stem from the use of the RATC-II, to evaluate the decision making process. Far as we know, this task has not been used before in studies of decision making and/or emotional assessment among bilinguals. However, this might not be the case, because the scores of the RATC-II were in favor of our hypothesis. This method might be less biased, since the participant doesn't encounter any prior words that might prime him or her to choose a specific answer, as opposed to the common decision making task the “Asian disease” problem (Kahneman \& Taversky, 1979; Keysar et al., 2012). To support the above claim, we asked the majority of the participants following their partaking if they had any assumption about the purpose of the study, none of them knew what the purpose was (results not shown).

Finally, there might have been an undesired effect by one of the RATC-II images. The majority of the responses to that image were of unusual or of atypical nature according to the RATC-II coding system. To address this issue we replaced the image with another one. Although the current study is comprised of the previous image and the new one, the results did not differ in nature from the preliminary ones that included only the old image (results not shown). We did not ran a statistical analysis due to the low number of participants.

Limitations: A major limitation of our study might be due to the early age of acquisition among our subjects. Most of them (82\%) have started learning English at schools around the age of 10. According to the literature they will be considered early bilinguals and not late bilinguals. The cutoff for late bilinguals is set at the age 12 because studies show that it is easier to acquire a second language in terms of pronunciation and grammar skills before that age (Abrahamsson, 2012). However, it doesn't necessarily mean that there is a difference in the emotional value given before and after the age of 12 to the different languages.

\section{Conclusion}

The bilingual's experiences in the different tongues are more complex than we've theorized before. Although we did find a significant emotional difference in the context of our subjects' stories, the electrophysiological measures told us a different story. Although we were not able to demonstrate an emotional detachment effect on a physiological level, we believed that holding the anxiety variable constant will yield that effect in future studies. Also, future studies should try to integrate the same methods used in prior research to measure the decisionmaking process (i.e. the Asian disease, gambling tasks, etc.) alongside electrophysiological measures, and incorporate different native tongues and foreign languages. 


\section{References}

Abrahamsson, N. (2012). Age of Onset and Nativelike L2 Ultimate Attainment of Morphosyntactic and Phonetic Intuition. Studies in Second Language Acquisition, 34, 187-214. http://dx.doi.org/10.1017/S0272263112000022

Adolphs, R. (2006). How Do We Know the Minds of Others? Domain-Specificity, Simulation, and Enactive Social Cognition. Brain Research, 1079, 25-35. http://dx.doi.org/10.1016/j.brainres.2005.12.127

Altarriba, J. (2002). Bilingualism: Language, Memory and Applied Issues. Online Readings in Psychology and Culture, 4, 1. http://dx.doi.org/10.9707/2307-0919.1034

Anooshian, L. J., \& Hertel, P. T. (1994). Emotionality in Free Recall: Language Specificity in Bilingual Memory. Cognition \& Emotion, 8, 503-514. http://dx.doi.org/10.1080/02699939408408956

Appelhans, B. M., \& Luecken, L. J. (2006). Heart Rate Variability as an Index of Regulated Emotional Responding. Review of General Psychology, 10, 229-240. http://dx.doi.org/10.1037/1089-2680.10.3.229

Argaman, O., \& Abu-Rabia, S. (2002). The Influence of Language Anxiety on English Reading and Writing Tasks among Native Hebrew Speakers. Language Culture and Curriculum, 15, 143-160. http://dx.doi.org/10.1080/07908310208666640

Bechara, A., Damasio, H., Damasio, A. R., \& Lee, G. P. (1999). Different Contributions of the Human Amygdala and Ventromedial Prefrontal Cortex to Decision-Making. The Journal of Neuroscience, 19, 5473-5481.

Beck, A. T., Steer, R. A., \& Brown, G. K. (1996) Manual for Beck Depression Inventory-II. San Antonio, TX: Psychological Corporation.

Ben-Zur, H. (1998). Strategies of Coping with Stress: The Adaptation of the Complete Hebrew Version of the COPE Inventory (Working Paper). In H. Ben-Zur (Ed.), The Effectiveness of Coping Meta-Strategies: Perceived Efficiency, Emotional Correlates and Cognitive Performance. Personality and Individual Differences, 26, 923-939. (In Hebrew) http://dx.doi.org/10.1016/S0191-8869(98)00198-6

Bialystok, E. (2010). Bilingualism. Wiley Interdisciplinary Reviews: Cognitive Science, 1, 559-572.

Bingham, W. E. (1943). A Study of the Relations Which the Galvanic Skin Response and Sensory Reference Bear to Judgments of the Meaningfulness, Significance, and Importance of 72 Words. The Journal of Psychology, 16, 21-34. http://dx.doi.org/10.1080/00223980.1943.9917159

Blanchette, I., \& Richards, A. (2010). The Influence of Affect on Higher Level Cognition: A Review of Research on Interpretation, Judgment, Decision Making and Reasoning. Cognition \& Emotion, 24, 561-595. http://dx.doi.org/10.1080/02699930903132496

Bowers, J. S., \& Pleydell-Pearce, C. W. (2011). Swearing, Euphemisms, and Linguistic Relativity. PLoS ONE, 6, e22341. http://dx.doi.org/10.1371/journal.pone.0022341

Burns, N. (2013). Cardiovascular Physiology. Retrieved from School of Medicine, Trinity College, Dublin. http://www.medicine.tcd.ie/physiology/assets/docs12_13/lecturenotes/NBurns/Trinity\%20CVS\%20lecture\%201-ECG\%2 012.13.ppt\%20(Read-Only).pdf

Caldwell-Harris, C. L., \& Aycicegi-Dinn, A. (2009). Emotion and Lying in a Non-Native Language. International Journal of Psychophysiology, 71, 193-204. http://dx.doi.org/10.1016/j.ijpsycho.2008.09.006

Critchley, H. D. (2002). Book Review: Electrodermal Responses: What Happens in the Brain? The Neuroscientist, 8, 132142. http://dx.doi.org/10.1177/107385840200800209

Davidson, R. J., \& Irwin, W. (1999). The Functional Neuroanatomy of Emotion and Affective Style. Trends in Cognitive Sciences, 3, 11-21. http://dx.doi.org/10.1016/S1364-6613(98)01265-0

De Martino, B., Kumaran, D., Seymour, B., \& Dolan, R. J. (2006). Frames, Biases, and Rational Decision-Making in the Human Brain. Science, 313, 684-687. http://dx.doi.org/10.1126/science.1128356

Dewaele, J. M. (2010). Emotions in Multiple Languages. London: Palgrave Macmillan. http://dx.doi.org/10.1057/9780230289505

Epstein, S. (1994). Integration of the Cognitive and the Psychodynamic Unconscious. American Psychologist, 49, $709-724$. http://dx.doi.org/10.1037/0003-066X.49.8.709

Freud, S. (1893). The Psychical Mechanisms of Hysterical Phenomena. London: Hogarth Press.

Groves, D. A., \& Brown, V. J. (2005). Vagal Nerve Stimulation: A Review of Its Applications and Potential Mechanisms That Mediate Its Clinical Effects. Neuroscience \& Biobehavioral Reviews, 29, 493-500. http://dx.doi.org/10.1016/j.neubiorev.2005.01.004

Halberstadt, A. (1994). On the Use of Language in Psychotherapy with Emigres from the Former Soviet Union. Journal of Jewish Communal Service, 71, 93-99.

Harris, C. L. (2004). Bilingual Speakers in the Lab: Psychophysiological Measures of Emotional Reactivity. Journal of Multilingual and Multicultural Development, 25, 223-247. http://dx.doi.org/10.1080/01434630408666530 
Harris, C. L., Aycicegi, A., \& Gleason, J. B. (2003). Taboo Words and Reprimands Elicit Greater Autonomic Reactivity in a First Language than in a Second Language. Applied Psycholinguistics, 24, 561-579.

http://dx.doi.org/10.1017/S0142716403000286

Hugdahl, K. (1995). Psychophysiology: The Mind-Body Perspective. Cambridge, MA: Harvard University Press.

Kahneman, D., Lovallo, D., \& Sibony, O. (2011). Before You Make That Big Decision. Harvard Business Review, 89, 5060.

Kahneman, D., \& Tversky, A. (1979). Prospect Theory: An Analysis of Decision under Risk. Econometrica: Journal of the Econometric Society, 47, 263-292. http://dx.doi.org/10.2307/1914185

Keysar, B., Hayakawa, S. L., \& An, S. G. (2012). The Foreign-Language Effect Thinking in a Foreign Tongue Reduces Decision Biases. Psychological Science, 23, 661-668. http://dx.doi.org/10.1177/0956797611432178

MacIntyre, P. D., \& Gardner, R. C. (1989). Anxiety and Second Language Learning: Toward a Theoretical Clarification. Language Learning, 39, 251-275. http://dx.doi.org/10.1111/j.1467-1770.1989.tb00423.x

Manning, S. K., \& Melchiori, M. P. (1974). Words That Upset Urban College Students: Measured with GSRs and Rating Scales. The Journal of Social Psychology, 94, 305-306. http://dx.doi.org/10.1080/00224545.1974.9923225

Marcos, L. R. (1976). Bilinguals in Psychotherapy: Language as an Emotional Barrier. American Journal of Psychotherapy, 30, 552-560.

Medin, D. L., Busemeyer, J. \& Hastie, R. (1995). Decision Making from a Cognitive Perspective: Advances in Research and Theory. San Diego, CA: Academic Press.

McDonald, R. J., \& Spielberger, C. D. (1983). Measuring Anxiety in Hospitalized Geriatric Patients. Series in Clinical \& Community Psychology: Stress \& Anxiety, 2, 135-143.

McGinnies, E. (1949). Emotionality and Perceptual Defense. Psychological Review, 56, 244-251. http://dx.doi.org/10.1037/h0056508

Movahedi, S. (1996). Metalinguistic Analysis of Therapeutic Discourse: Flight into a Second Language When the Analyst and the Analysand Are Multilingual. Journal of the American Psychoanalytic Association, 44, 837-862.

Naqvi, N., Shiv, B., \& Bechara, A. (2006). The Role of Emotion in Decision Making: A Cognitive Neuroscience Perspective. Current Directions in Psychological Science, 15, 260-264. http://dx.doi.org/10.1111/j.1467-8721.2006.00448.x

National Institute for Testing and Evaluation (Last Updated 2013). December 2011 Test Form. https://www.nite.org.il/files/psych/psychometric dec 2011 hebrew.pdf

Pappamihiel, N. E. (2002). English as a Second Language Students and English Language Anxiety: Issues in the Mainstream Classroom. Research in the Teaching of English, 36, 327-355.

Pavlenko, A. (2005). Bilingualism and Thought. In A. M. B. De Groot, \& J. F. Kroll (Eds.), Handbook of Bilingualism: Psycholinguistic Approaches (pp. 433-453). Oxford: Oxford University Press.

Pavlenko, A. (2012). Affective Processing in Bilingual Speakers: Disembodied Cognition? International Journal of Psychology, 47, 405-428. http://dx.doi.org/10.1080/00207594.2012.743665

Pumprla, J., Howorka, K., Groves, D., Chester, M., \& Nolan, J. (2002). Functional Assessment of Heart Rate Variability: Physiological Basis and Practical Applications. International Journal of Cardiology, 84, 1-14. http://dx.doi.org/10.1016/S0167-5273(02)00057-8

Quintana, D. S., Guastella, A. J., Outhred, T., Hickie, I. B., \& Kemp, A. H. (2012). Heart Rate Variability Is Associated with Emotion Recognition: Direct Evidence for a Relationship between the Autonomic Nervous System and Social Cognition. International Journal of Psychophysiology, 86, 168-172. http://dx.doi.org/10.1016/j.ijpsycho.2012.08.012

Roberts, G. E. (2013). Roberts Apperception Test for Children: 2. http://www.mhs.com/product.aspx?gr=edu\&prod=roberts2\&id=overview

Schwanberg, J. S. (2010). Does Language of Retrieval Affect the Remembering of Trauma? Journal of Trauma and Dissociation, 11, 44-56. http://dx.doi.org/10.1080/15299730903143550

Shachar, K. (2005). The Link between Self-Control, Social Support and Subjective Wellbeing of Teachers in Miftans. Unpublished Doctoral Dissertation, Tel-Aviv: Tel-Aviv University.

Simon, H. A. (1956). Rational Choice and the Structure of the Environment. Psychological review, 63, 129-138. http://dx.doi.org/10.1037/h0042769

Slovic, P., Finucane, M. L., Peters, E., \& MacGregor, D. G. (2007).The Affect Heuristic. European Journal of Operational Research, 177, 1333-1352. http://dx.doi.org/10.1016/j.ejor.2005.04.006

Spielberger, C. D., Gorsuch, R. L., \& Lushene, R. E. (1970). State-Trait Anxiety Inventory: STAI. Palo Alto, CA: Consulting Psychologists Press.

Tversky, A., \& Kahneman, D. (1974). Judgment under Uncertainty: Heuristics and Biases. Science, 185, 1124-1131. 
http://dx.doi.org/10.1126/science.185.4157.1124

Watson, D., Clark, L. A., \& Tellegen, A. (1988). Development and Validation of Brief Measures of Positive and Negative Affect: The PANAS Scales. Journal of Personality and Social Psychology, 54, 1063-1070. http://dx.doi.org/10.1037/0022-3514.54.6.1063

Woodrow, L. (2006). Anxiety and Speaking English as a Second Language. RELC Journal, 37, 308-328. http://dx.doi.org/10.1177/0033688206071315

Vecchiato, G., Astolfi, L., Fallani, F. D. V., Cincotti, F., Mattia, D., Salinari, S., Babiloni, F. et al. (2010). Changes in Brain Activity during the Observation of TV Commercials by Using EEG, GSR and HR Measurements. Brain Topography, 23, 165-179. http://dx.doi.org/10.1007/s10548-009-0127-0

Zajonc, R. B. (1980). Feeling and Thinking: Preferences Need No Inferences. American Psychologist, 35, 151-175. http://dx.doi.org/10.1037/0003-066X.35.2.151 
Scientific Research Publishing (SCIRP) is one of the largest Open Access journal publishers. It is currently publishing more than 200 open access, online, peer-reviewed journals covering a wide range of academic disciplines. SCIRP serves the worldwide academic communities and contributes to the progress and application of science with its publication.

Other selected journals from SCIRP are listed as below. Submit your manuscript to us via either submit@scirp.org or Online Submission Portal.
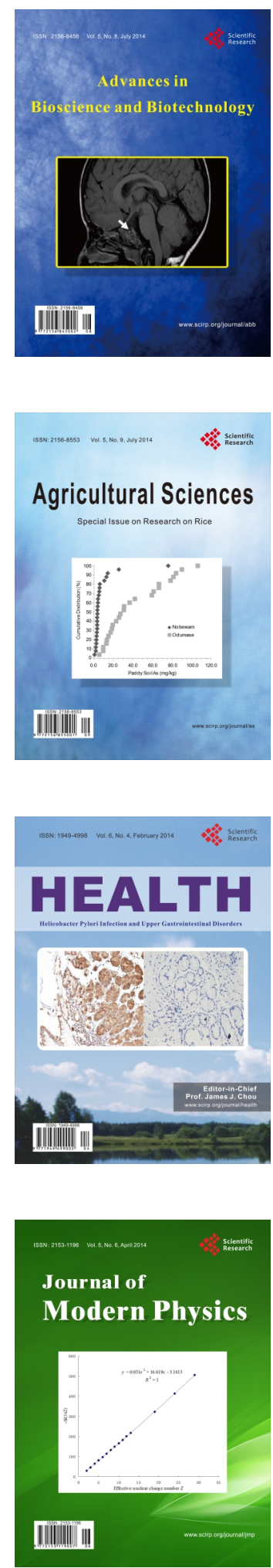
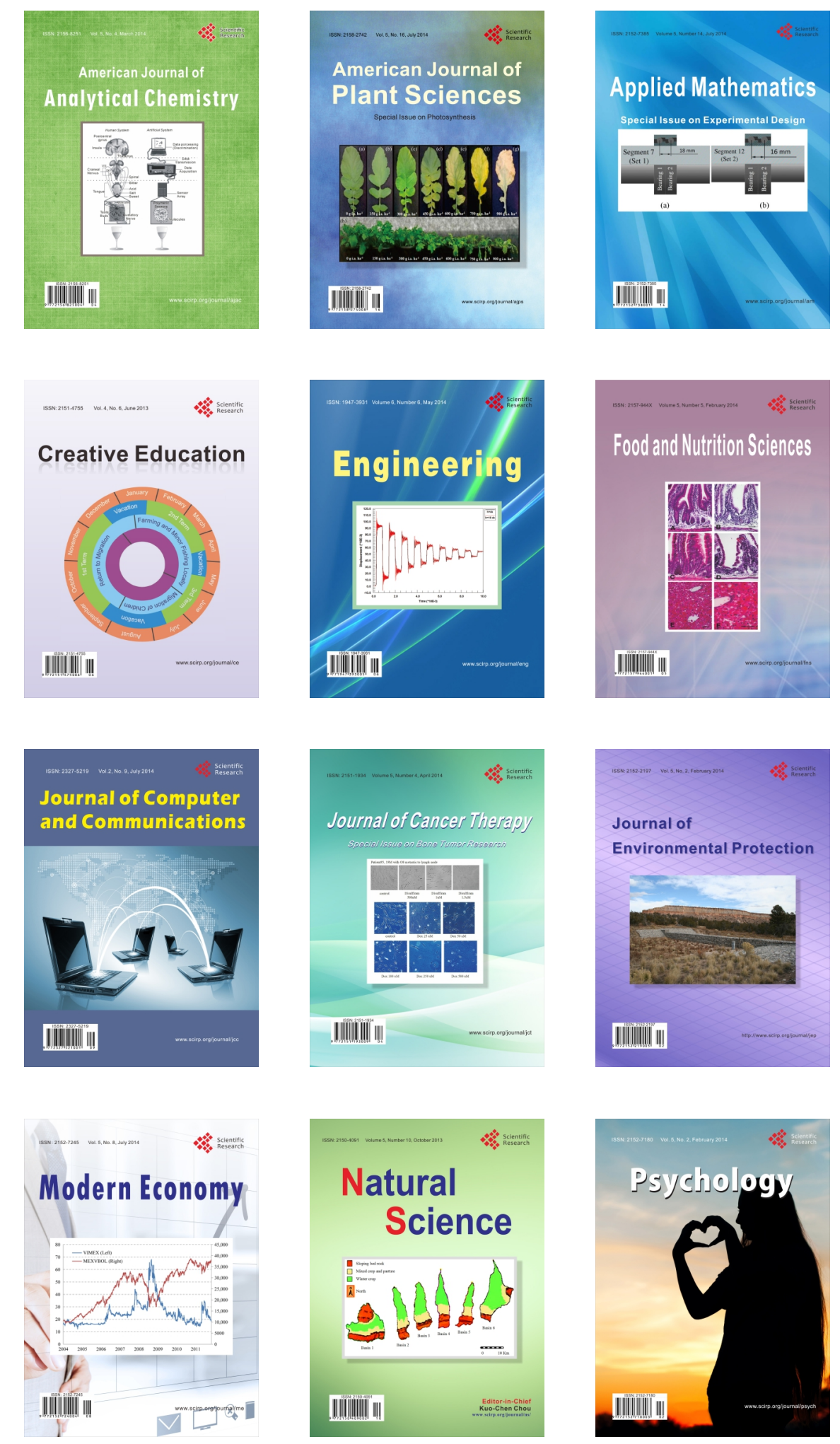